\title{
En kvinnes reproduksjon og hennes livslengde - er der noen sammenheng?
}

\author{
Rolv Skjærven \\ Folkehelseinstituttet og Universitetet $i$ Bergen \\ rolv.skjarven@uib.no
}

This is an open access article distributed under the Creative Commons Attribution Licence, which permits unrestricted use, distribution, and reproduction
in any medium, provided the original work is properly cited.

Mødredødelighet er definert av WHO som dødsfall i løpet av svangerskapet eller innen 42 dager etter fødsel. I en fersk Nordisk studie rapporterte Vangen et al. 37 dødsfall i Norge for perioden 2005-2013 ${ }^{1}$. For landene samlet var der 7,2 dødsfall per 100.000 fødsler, og liten variasjon mellom landene. Forskere har stilt spørsmål om denne 42 dagers grensen, spesielt ut ifra situasjonen i utviklingsland ${ }^{2}$.

I det siste desennium har vi sett mange studier som dokumenterer sammenhengen mellom svangerskapskomplikasjoner og mors langtidshelse. De fleste studiene evaluerer komplikasjoner i forhold til hjertekardød (CVD-død). Dødsfallene observeres 10 år etter indeks-svangerskapet ${ }^{3}$, og den økte risikoen er sterkere tidlig i livsløpet, 40-49 års alder, heller enn sent, 70+ år ${ }^{3}$. Janet Rich-Edwards et al. ${ }^{4}$ har gitt en systematisk oversikt over sammenhenger mellom svangerskapsutfall og kvinners fremtidige helse, med vekt på kardiovaskulære problemer.

\section{SVANGERSKAPSFORGIFTNING - SØSKENDATA OG LANG OPPFØLGING}

Svangerskapsforgiftning (preeklampsi) er komplikasjonen som har hatt sterkest fokus, og en serie med oversiktsartikler har konkludert med at kvinner med denne komplikasjonen har en doblet risiko for å dø tidlig (2-fold hasard). ${ }^{5-7}$ Dette ser vi også i norske data, men et slikt tverrsnittsestimat sier lite om den enkelte kvinnes langtidsrisiko.

For å studere sammenhengen mellom mors svangerskapskomplikasjoner og langtidshelse har vi kommet frem til at studieenheten bør være 'mor og hennes totale reproduksjon', og ikke 'et svangerskap' (vanligvis velges første svangerskap). Hvorfor er dette viktig? Mors langtidshelse modifiseres ved ytterligere svangerskap $^{3}$. Hvis komplikasjonen ikke gjentar seg, er mors prognose langt bedre enn hos kvinner som kun har ett svangerskap. Derimot ser vi at kombinasjonen preterm fødsel og preeklampsi i andre svangerskap øker risikoen vesentlig, men her uavhengig av hendelser $i$ første svangerskap. Disse og tilsvarende variasjoner i svangerskapsutfall viser heterogenitet i risiko, en heterogenitet som kun kan vurderes dersom data gir muligheter for å følge en kvinnes suksessive svangerskap over tid.

For at studier skal kunne gi riktig effekt av kvinners reproduksjon på langtidshelse, trengs i tillegg lang oppfølgingstid. I norske data finner vi at $95 \%$ av mødre med to eller flere fødsler har sin andre fødsel innen 7 år etter den første. Data med kortere oppfølging vil derfor ikke være optimale ${ }^{3}$. Kort oppfølging vil gi et materiale som preges av dødsfall blant relativt unge kvinner, og preeklampsi vil kunne dominere blant dødsårsaker fordi referanse-dødeligheten blir særs lav. Med kort oppfølgning blir dermed hasard ratio kunstig høy. I Tabell 1 viser vi hvordan variasjon i oppfølgingstid og tidspunkt for første fødsel gir store effektforskyvninger.

Komplikasjoner i svangerskapet kan være uttrykk for eksisterende helseforhold som er uavhengig av svangerskapet. Dersom mor har høy BMI øker risiko for preeklampsi og svangerskapsdiabetes. Vi vet at preeklampsi kan være arvelig, både fra mors og fars side $^{8}$. Komplikasjoner under svangerskapet kan og gi varig skade, uavhengig av arvelige forhold - for eksempel er preeklampsi relatert til senere nyresykdom. I søskenstudier har vi funnet sterke relasjoner mellom preeklampsi og nyreskade (ESRD), men ingen økt risiko hos uaffiserte søstre? gen for preeklampsi ikke i seg selv vil gi nyreskade, en må ha vært eksponert for komplikasjonen i ett eller flere svangerskap.

Allerede i 1976 fant Leon Chesley at preeklampsi i senere svangerskap, relativt preeklampsi i første svangerskap, var forbundet med høyere risiko ${ }^{10,11}$. På tross av dette er de fleste nyere studier basert på risiko ved første svangerskap. Oversiktsartikler konkluderer med en doblet risiko for CVD-død etter preeklampsi, mens vi finner høy heterogenitet i risiko - fra hasard ratio 1,3 for kvinner med flere svangerskap og preeklampsi

Table 1. Maternal cardiovascular mortality, age 40-69 years, by preeclampsia in $1^{\text {st }}$ pregnancy (none, preterm or term) and one or two or more pregnancies; with varying periods for $1^{\text {st }}$ birth and follow-up years.

\begin{tabular}{llccc} 
& & Year 1st birth & $1967-76$ & $1977-86$ \\
& & Follow-up years & $1967-14$ & $1977-14$ \\
\multicolumn{2}{c}{ Conditions } & Pregnancies & Hazard ratio \\
no preecl. term & $2+$ & $\mathbf{1}$ & $\mathbf{1}$ \\
preeclampsia & preterm & $2+$ & $\mathbf{1 , 6}$ & $\mathbf{3 , 9}$ \\
preeclampsia & term & $2+$ & $\mathbf{1 , 3}$ & $\mathbf{1 , 9}$ \\
no preecl. & term & 1 & $\mathbf{1 , 6}$ & $\mathbf{2 , 2}$ \\
preeclampsia & preterm & 1 & $\mathbf{4 , 2}$ & $\mathbf{1 1 , 9}$ \\
preeclampsia & term & 1 & 3,1 & 4,9
\end{tabular}

Follow-up years: both maternal death and further reproduction 
til termin i første svangerskap, til 11,3 for kvinner med kun et svangerskap affisert av preeklampsi og preterm fødsel (Tabell 1). I Norge får $85 \%$ av mødre mer enn ett svangerskap. Tabellen viser at med kun et svangerskap er risiko høy. Referansegruppe er kvinner med 2 eller flere barn uten preeklampsi i første svangerskap.

\section{Perinatal død}

For de første 5 årene i Medisinsk fødselsregister (19671971) var perinatal dødelighet høy for barn av mødre med preeklampsi (4-fold) og spesielt der mor hadde preterm-preeklampsi (20-fold). For de fleste kvinner vil et 'erstatningsbarn' være den åpenbare responsen for en slik uønsket hendelse, og $\mathrm{i}$ våre data ser vi at fertiliteten øker for kvinner som har mistet et barn ${ }^{12}$. Et naturlig spørsmål vil være: reduseres overdødeligheten etter et perinatalt dødsfall dersom mor fortsetter sin reproduksjon etter et tap?

Perinatal død har betydning for mors langtidshelse, og en nylig publisert studie av en dansk forskningsgruppe $^{13}$ fant en $80 \%$ økning i total dødelighet for mor etter et perinatal tap, og 120\% økning for CVD-død, dvs. igjen en doblet risiko.

Denne studien tok ikke hensyn til hva som skjer senere: er dette mors eneste svangerskap, har hun et nytt tap, eller blir barnet som døde 'erstattet' av et nytt svangerskap der barnet overlever? Som for svangerskapforgiftning finner vi store heterogeniteter i risiko nettopp i forhold til 'hva skjer etter det perinatale tapet ${ }^{14}$. I Figur 1 viser vi variasjon i mors CVD-død (hasard ratio, HR) basert på kvinner med et, to eller tre svangerskap (enkeltfødte, 1967-2014 data). Høyest risiko observerer vi når mor føder et barn som dør perinatalt og dette ikke 'erstattes'.

\section{FOR TIDLIG FØDSEL (PRETERM)}

Også tidlig fødsel (før 37. svangerskapsuke) rapporteres å være forbundet med doblet risiko for CVD-død ${ }^{15}$. I vår studie tar vi hensyn til om det tidlige svangerskapet var indusert eller en følge av spontan start av fødsel ${ }^{16}$. Vi vurderer også effekt av svært preterm og om gjentagelse av preterm fødsel påvirker risikoen for mors langtidshelse. Preterm i første svangerskap og ingen flere svangerskap er igjen relatert til høy hasard $(4,2)$; preterm også i andre svangerskap gir likeledes relativt høy hasard $(3,3)$; men preterm fødsel, fulgt av et termin svangerskap, gir redusert hasard $(1,5)$. Indusert preterm fødsel, spesielt uke 35-36, gir den høyeste hasarden $(6,2)$ i analyser der vi tar hensyn til spontan/indusert fødsel samtidig som vi stratifiserer risiko etter svangerskapvarighets kategorier.

\section{MORKAKELØSNING (ABRUPTIO PLACENTA)}

Morkakeløsning er sterkt relatert til preterm fødsel og til perinatal død. Effekten av abruptio i seg selv på mors langtidshelse, utover disse to faktorene, er vanskelig på grunn av sammenfall av hendelser. For

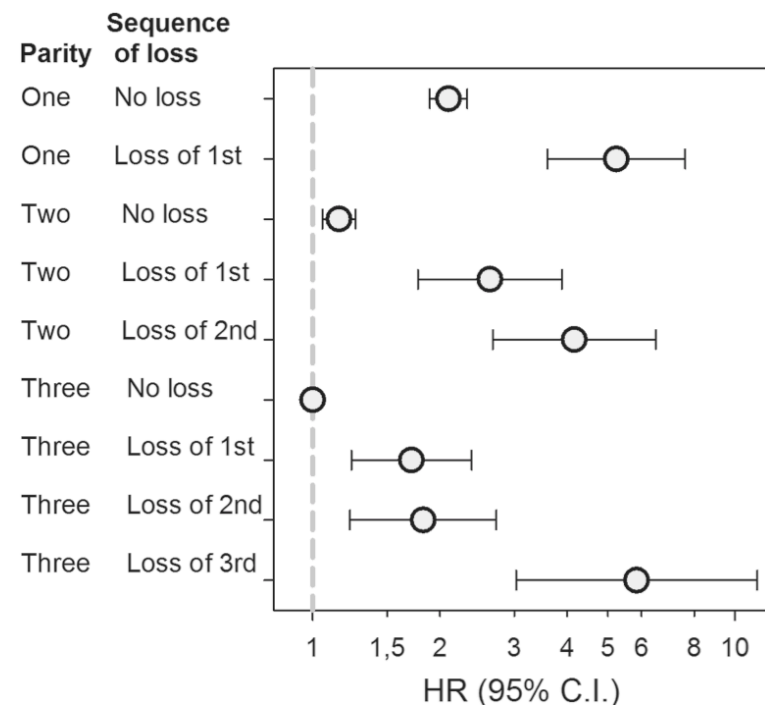

Figur 1. Maternal cardiovascular mortality, age 40-69 years, by perinatal loss of $1^{\text {st }}, 2^{\text {nd }}$ or $3^{\text {rd }}$ birth, Norway 1967-1996 (1st births). Reproduction and mortality up to end of 2014.

førstefødte i 1967-76 var 52\% av abruptio affiserte svangerskap preterm. Samme andel preterm fant vi for de 10 siste årene av vårt materiale, 2005-2014. Andelen preterm for kvinner uten abruptio var $6 \%$ i begge perioder. På den andre siden observerer vi en sterk reduksjon i perinatal $\mathrm{d} ø \mathrm{~d}-43 \%$ i første periode, mot $7,5 \%$ i siste periode. Denne reduksjonen har vært sterkere enn for uaffiserte svangerskap, fra $1,9 \%$ til $0,6 \%$, respektiv.

Abruptio er en sjelden tilstand, og forekomsten (første fødsel) var hhv. $0,5 \%$ og $0,3 \%$ for de to periodene. For å få tilstrekkelig styrke i data samarbeidet vi med svenske forskere ${ }^{17}$. Vi fant at abruptio i forste svangerskap ved termin fødsel ikke i vesentlig grad økte mors risiko for tidlig CVD-død (30\% økt risiko, ikke signifikant). Effekten var sterkere ved preterm fødsel (hasard ratio 2,3). For mødre med kun et svangerskap var risikoen litt høyere enn for mødre med abruptio i første svangerskap og senere flere fødsler, 2,6 versus 2,1 . Disse forskjellene viser ikke den samme sterke heterogenitetet som vi fant for preeklampsi og perinatal død.

\section{FØDSELSVEKT OG MORS LANGTIDSHELSE}

I en serie med artikler har George Davey Smith vurdert sammenhengen mellom barnets fødselsvekt og mors langtidshelse, og konkluderte i en reviewartikkel med at CVD-død reduseres med $13 \%$ for hver standardavvik-økning i barnets fødselsvekt. ${ }^{18}$ Dette blir litt abstrakt, men om median fødselsvekt antas å være $3500 \mathrm{~g}$ vil en fødselsvekt på $3000 \mathrm{~g}$ svare til 13\% økt dødelighet, og $2500 \mathrm{~g}$ svare til 26\% økning (forutsatt et standard avvik på $500 \mathrm{~g}$ ). Med høyere fødselsvekt, for eksempel $4500 \mathrm{~g}$, vil mors livslengde øke med $26 \%$. 


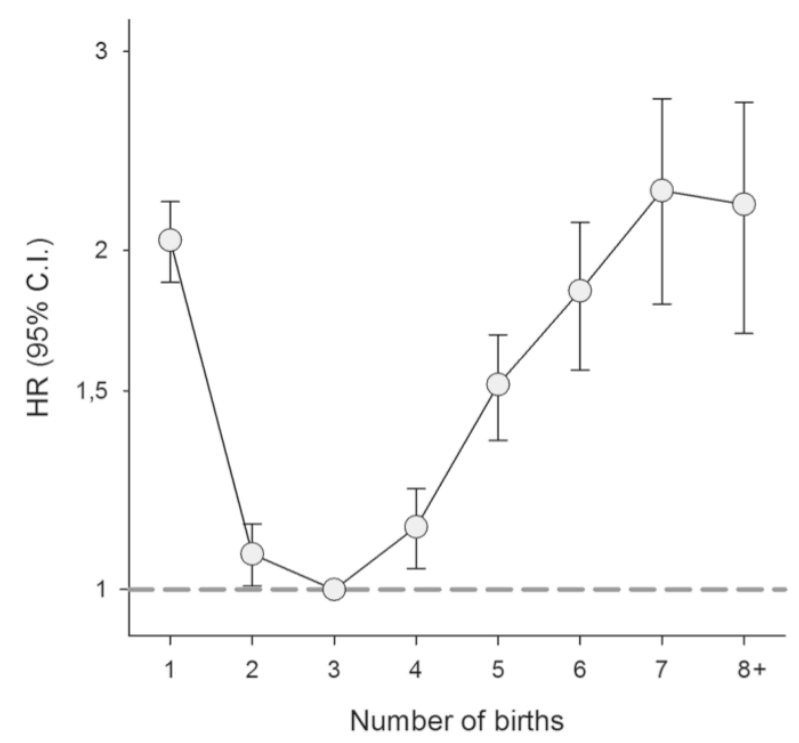

Figur 2. Maternal cardiovascular mortality, age 40-69 years, by number of births, Norway 1967-1996 (1st births). Reproduction and mortality up to end of 2014.

De fleste studier evaluerer effekten av absolutt fødselsvekt, spesielt for første barn, og uten å ta hensyn til svangerskapets lengde. Vi valgte å analysere fødselsvekt relativt svangerskapsvarighet (vha. Z-scores) ${ }^{19}$. Den monotone reduksjonen i risiko for økende fødselsvekt ble brudt for høye z-scores, og ved å stratifisere på term/preterm observerte vi økt CVD-død hos mor med preterm fødsel og høye z-scores. I en subanalyse fant vi, for denne siste gruppen kvinner, en økt risiko for diabetes ved neste svangerskap.

\section{ANTALL SVANGERSKAP (PARITET) OG CVD- RISIKO FOR MOR}

De fleste som har studert mors langtidshelse og antall barn finner at dødeligheten er høyest med mange barn. For eksempel i en fersk studie fra Sverige var konklusjonen at risikoen følger et J-formet risikomønster, lavest risiko etter to barn, og høyest etter 5 eller flere $\operatorname{barn}^{20}$.

Vi har nylig studert paritet og CVD-risiko, og vi finner de samme trendene som tidligere studier har rapportert (Figur 2) ${ }^{21}$. Kåre Cristensen et al. foreslår «A tooth for a child» (en tann for et barn) for å illustrere kostnadene for mor ved å føde barn - barnefødsler koster litt helse ${ }^{22}$.

Det er vanlig i slike studier å 'justere' for faktorer som vi mener har konfunderende betydning (Konfundere: en faktor som er assosiert med både eksponerings- og utfallsvariabel), for eksempel mors utdannelse. Istedenfor å justere for utdannelse valgte vi å stratifisere for hhv. lav og høy utdannelse, og resultatet var overraskende. Resultatene bryter med tidligere resultater, og vår konklusjon er: Det er ikke riktig at mors dødelighet øker med økende antall barn, i hvert fall innenfor variasjonen fra 1 til 4 barn - som dekker 98\% av mødre i Norge (førstefødte 1967-96).

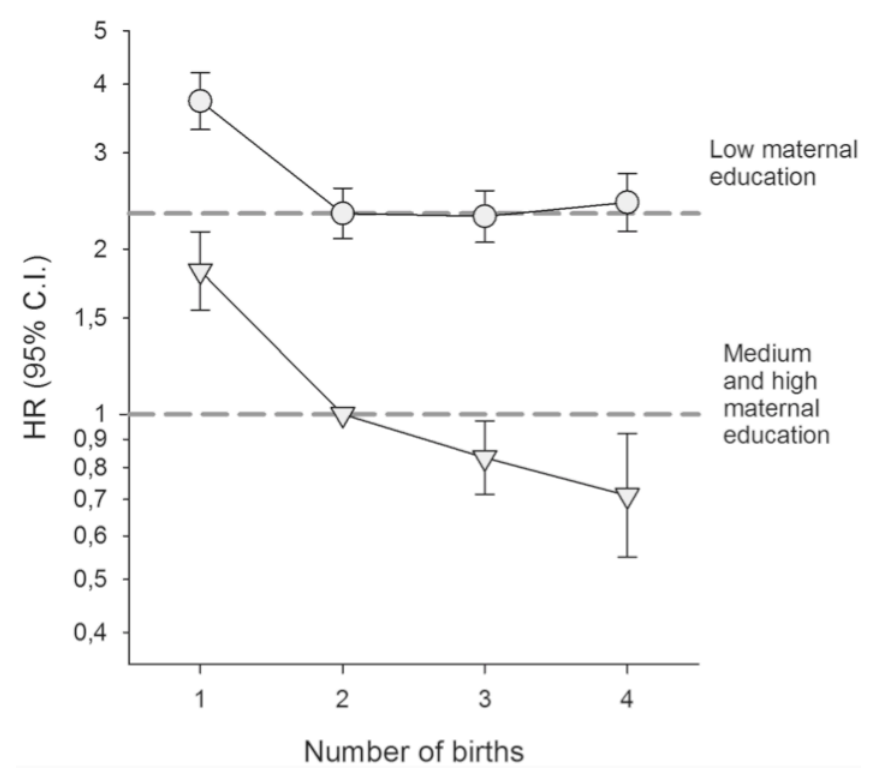

Figur 3. Maternal cardiovascular mortality, age 40-69 years, by number of births, in two maternal education strata. Norway 1967-1996 (1st births), reproduction and mortality up to end of 2014.

Våre ferske resultater viser at det ikke lenger er slik i Norge at mor dør av å føde mange barn, og spesielt observerer vi, at med høy utdannelse (videregående eller universitets-utdanning), reduseres faktisk CVDdød signifikant for kvinner som har tre eller fire barn når risikoen sammenholdes mot kvinner med to barn (Figur 3) ${ }^{21}$.

Vi ser at dødeligheten generelt er høyere for mødre med lav utdannelse, men selv her er der ingen tendens til høyere risiko for kvinner med 3 eller 4 barn. Imidlertid er der for begge utdannelsesstrata en klar overdødelighet for kvinner med kun et barn, slik vi tidligere har rapportert for kvinner med preeklampsi.

Sammenholder vi de to kurvene ser vi at forklaringen for de forskjellige bildene er at kvinner med lav utdannelse er de som har mange barn (5+), i tillegg finner vi at relativt flere med lav utdannelse også får 3 og 4 barn.

I sin reviewartikkel ${ }^{4}$ foreslår Rich-Edwards et al. tre mulige mekanismer som kan være årsaken til den observerte økningen for mors CVD-død relatert til mange barn: 1) fysiologiske forandringer i mor akkumulerer seg for hvert barn, 2) ugunstige livsstilsvaner akkumulerer seg (BMI?), og 3) seleksjonsbias, ved at kvinner med høy CVD-risk velger å få mange barn. Med basis i våre stratifiserte resultater er der god støtte for seleksjonsbias, drevet av variasjon i livsstil.

\section{DATA}

Våre analyser (refererte artikler) er basert på data fra Medisinsk fødselsregister (MFR) for perioden 19672009, koblet med Dødsårsaksregisteret og SSBs utdanningsregister. MFR-data er organisert i søskenstrukturer. I de fleste analysene fokuserer vi på dødsfall ved 
alder 40-69 år. Vi tok ut de unge under 40 slik at vi studerer kun kvinner som er ferdig med sin reproduksjon. Dødsfall ved 70 år eller over er ekskludert fordi ved denne alderen er effekter av svangerskapskomplikasjoner svake. De tre figurene og tabellen er basert på oppdaterte data (periode 19672014), med design som beskrevet i de publiserte artiklene. Figurene er basert på data for mødre med førstefødte i perioden 1967-1996, med oppfølging for senere reproduksjon, utdanning og dødelighet til avslutning av 2014. Alle estimater vi rapporterer over er signifikant (5\% nivå), om ikke annet er beskrevet. Studiene er godkjent av REK Vest (prosjekt 2015/1728 og 2009/1868).

\section{REFERANSER}

1. Vangen S, Bodker B, Ellingsen L, et al. Maternal deaths in the Nordic countries. Acta Obstet Gynecol Scand 2017; 96: 1112-9.

2. Hoj L, da Silva D, Hedegaard K, Sandström A, Aaby P. Maternal mortality: only 42 days? BJOG 2003; 110: 995-1000.

3. Skjærven R, Wilcox AJ, Klungsøyr K, et al. Cardiovascular mortality after pre-eclampsia in one child mothers: prospective, population based cohort study. BMJ 2012; 345: e7677.

4. Rich-Edwards JW, Fraser A, Lawlor DA, Catov JM. Pregnancy characteristics and women's future cardiovascular health: an underused opportunity to improve women's health? Epidemiol Rev 2014; 36: 57-70.

5. Bellamy L, Casas JP, Hingorani AD, Williams DJ. Pre-eclampsia and risk of cardiovascular disease and cancer in later life: systematic review and meta-analysis. BMJ 2007; 335: 974.

6. McDonald SD, Malinowski A, Zhou Q, Yusuf S, Devereaux PJ. Cardiovascular sequelae of preeclampsia/ eclampsia: a systematic review and meta-analyses. Am Heart J 2008; 156: 918-30.

7. Brown MC, Best KE, Pearce MS, Waugh J, Robson SC, Bell R. Cardiovascular disease risk in women with pre-eclampsia: systematic review and meta-analysis. Eur J Epidemiol 2013; 28: 1-19.

8. Skjærven R, Vatten LJ, Wilcox AJ, Rønning T, Irgens LM, Lie RT. Recurrence of pre-eclampsia across generations: exploring fetal and maternal genetic components in a population based cohort. BMJ 2005; $331: 877$.

9. Vikse BE, Irgens LM, Karumanchi SA, Thadhani R, Reisæter AV, Skjærven R. Familial factors in the association between preeclampsia and later ESRD. Clin J Am Soc Nephrol 2012; 7: 1819-26.

10. Chesley LC. Remote prognosis after eclampsia. Perspect Nephrol Hypertens 1976; 5: 31-40.

11. Chesley LC. Recognition of the long-term sequelae of eclampsia. Am J Obstet Gynecol 2000; 182: $249-50$.

12. Skjærven R, Wilcox AJ, Lie RT, Irgens LM. Selective fertility and the distortion of perinatal mortality. Am J Epidemiol 1988; 128: 1352-63.

13. Hvidtjørn D, Wu C, Schendel D, Thorlund Parner E, Brink Henriksen T. Mortality in mothers after perinatal loss: a population-based follow-up study. BJOG 2016; 123: 393-8.

14. Halland F, Morken NH, DeRoo LA, Klungsøyr K, Wilcox AJ, Skjærven R. Long-term mortality in mothers with perinatal losses and risk modification by surviving children and attained education: a population-based cohort study. BMJ Open 2016; 6: e012894.

15. Catov JM, Newman AB, Roberts JM, et al. Preterm delivery and later maternal cardiovascular disease risk. Epidemiology 2007; 18: 733-9.

16. Rich-Edwards JW, Klungsøyr K, Wilcox AJ, Skjærven R. Duration of pregnancy, even at term, predicts longterm risk of coronary heart disease and stroke mortality in women: a population-based study. Am J Obstet Gynecol 2015; 213: 518 e1-8.

17. DeRoo L, Skærven R, Wilcox A, et al. Placental abruption and long-term maternal cardiovascular disease mortality: a population-based registry study in Norway and Sweden. Eur J Epidemiol 2016; 31: 501-11.

18. Smith GD, Hypponen E, Power C, Lawlor DA. Offspring birth weight and parental mortality: prospective observational study and meta-analysis. Am J Epidemiol 2007; 166: 160-9.

19. Morken NH, Halland F, DeRoo LA, Wilcox AJ, Skjærven R. Offspring birthweight by gestational age and parental cardiovascular mortality: a population-based cohort study. BJOG 2017, doi: 10.1111/14710528.14522 [Epub ahead of print].

20. Parikh NI, Cnattingius S, Dickman PW, Mittleman MA, Ludvigsson JF, Ingelsson E. Parity and risk of laterlife maternal cardiovascular disease. Am Heart J 2010; 159: 215-21 e6.

21. Halland F, Morken NH, DeRoo LA, Klungsøyr K, Wilcox AJ, Skjærven R. Association of women's reproductive history with long-term mortality and effect of socioeconomic factors. Obstet Gynecol 2015; 126: 1181-7.

22. Christensen K, Gaist D, Jeune B, Vaupel JW. A tooth per child? Lancet 1998; 352: 204. 